\title{
Nutrients with Malnutrition-Sarcopenia
}

\author{
Ying Gao-Balch* and Diann Williams \\ Department of Human Science and Nursing, University of Arkansas, USA
}

Submission: October 13, 2017; Published: April 16, 2018

*Corresponding author: Ying Gao-Balch, Department of Human Science and Nursing, 1200 North University Drive University of Arkansas, Pine Bluff Arkansas 71601, USA, Tel: 8705757905; Email: gaobalchy@uapb.edu

\section{Abstract}

Prevention of age-related losses in muscle mass and strength is key to protecting physical capability in older age and enabling independent living. To develop preventive strategies, a better understanding is needed of the lifestyle factors that influence sarcopenia and the mechanisms involved. Existing evidence indicates the potential importance of diets of adequate quality, to ensure sufficient intakes of protein, vitamin D, and antioxidant nutrients. Although much of this evidence is observational, the prevalence of low nutrient intakes and poor status among older adults make this a current concern. However, as muscle mass and strength in later life are a reflection of both the rate of muscle loss and the peak attained in early life, efforts to prevent sarcopenia also need to consider diet across the lifetime and the potential effectiveness of early interventions. Optimizing diet and nutrition throughout life may be key to preventing sarcopenia and promoting physical capability in older age.

\section{Introduction}

Sarcopenia is a syndrome characterized by progressive and generalized loss of skeletal mass and strength with a risk for adverse outcomes such as physical disability, poor quality of life, and death [1-4]. It is a multifactorial process where nutrition, hormonal factors, lifestyle, and diseases exert an important role [5]. Apart from that, age-related loss of muscle mass is characterized by a $3 \%$ to $8 \%$ decline per decade after the age of $30 y$, with a further decline in adult's $\geq 60 y$ of age [6]. Epidemiologic data suggest that the prevalence of sarcopenia varies widely, depending on the population studied, sex, age, settings, and the diagnostic criteria used [4]. The prevalence of sarcopenia in nursing homes, according to the European Working Group on Sarcopenia in Older People (EWGSOP) criteria [7], is between 17 and $40.2 \%$ [5,8-12].

Sarcopenia and malnutrition are both commonly happening conditions in older adults. Both entities result in numerous and substantial negative outcomes to the patients and the health care system, including decreased quality of life and functionality, and increased health care costs, hospitalization rates, morbidity, and mortality [13]. Their clinical affect and the high direct and indirect costs input the need for health care systems to focus on these syndromes $[14,15]$.

Food intake falls by around $25 \%$ between 40 and 70 years of age [16]. In comparison with younger ages, older adults eat more slowly, they are less hungry and thirsty, consume smaller meals, and they snack less [16]. The mechanisms for the "anorexia of ageing" are not fully understood but there may be a person of physiological, psychological, and social factors that influence appetite and food consumption, including loss of taste and olfaction, increased sensitivity to the satiating effects of meals, chewing difficulties, and impaired gut function $[16,17]$. These changes are compounded by the effects of functional impairments that impact on the ability to access and prepare food, psychological problems such as depression and dementia, as well as the social effects of living and eating alone. Low food intakes and lacking in variety and interest diets put older people at risk of having inadequate nutrient intakes [18]. Thus in a serious of cause and effect, declining muscle strength and physical capability in older age may increase the risk of poor nutrition, and poor nutrition may contribute to further declines in physical capability.

In the ageing and sick population malnutrition that has been seen in hospitals, residential care and in the community [19-21]. Prevalence rates have been estimated for the general hospital population to be between $11 \%$ to $44 \%$, but this rises in elderly groups to $29 \%-61 \%$ [19]. Malnutrition is not an inevitable side effect of ageing, but many changes associated with the process of ageing can promote malnutrition [22]. For example, ageing is frequently associated with decreases in taste acuity and smell, deteriorating dental health, and decreases in physical activity, which may all affect nutrient intake [23]. Any change in nutrient intake can lead to malnutrition with its potentially serious consequences. Many studies have found a direct relation between the degree of malnutrition and increased length of stay, treatment costs, and re-admission to hospital rates [24-26]. Therefore the treatment and prevention of malnutrition, which is most common in the older age group, is an important challenge for the health care system. 


\section{Nutrients Influence on Sarcopenia and Malnutrition}

There are two consequences of cause older age for muscle mass and strength. Firstly, lower energy intakes, if not matched by lower levels of energy expenditure, lead to weight loss, including a loss of muscle mass [4]. Secondly, as older people consume smaller amounts of food, it may become more difficulty for them to meet their nutrient as they needs-particularly for micronutrients. For older people with low food intakes, this highlights the importance of having diets of adequate quality. Although the importance of adequate nutrition has been recommend for a long time, its contribution to muscle mass and strength has not been studied extensively and much of the research in this area is relatively new [27]. A number of interventions have been researched,people can be provided of nutritional supplementation with specific nutrients [28-30]. The nutrients that have been most consistently linked to sarcopenia and frailty in older adults are vitamin D, protein, and a number of antioxidant nutrients, that include carotenoids, selenium, and vitamins E and C [27]. However, there is also some evidence that variations in long-chain polyunsaturated fatty acid status may have important effects on muscle strength in older people [30].

\section{Protein and Vitamin D}

Protein is considered a key nutrient in older age [31]. Dietary protein provides amino acids that are needed for the synthesis of muscle protein, and importantly, absorbed amino acids have a stimulatory effect on muscle protein synthesis after feeding [32]. There is some evidence that the synthetic response to amino acid intake may be less in older people, particularly at low intakes [31], and when protein is consumed together with carbohydrate [33]. Recommended protein intakes may, therefore, need to be raised in older people in order to maintain nitrogen balance and to protect them from sarcopenia muscle loss [31].

There is currently no consensus on the level to which dietary protein requirements change in older age, there is an insufficient protein intake may be an important contributor to impaired physical function. Aging and Body Composition Study, a greater loss of lean mass over 3 years, assessed using dual-energy X-ray absorptiometry, was found among older community-dwelling men and women who had low energy-adjusted protein intakes at baseline [34]. Protein and/or amino acid supplementation should, therefore, have the potential to slow sarcopenia muscle loss. However, the amino acid supplementation has been shown to increase lean mass and improve physical function [35], other trials have not been successful [33,36]. Further need to work, including longer-term trials, is needed to define optimal protein intakes in older age [33].

An association between vitamin-D-deficient osteomalacia and myopathy has been identified for many years [37], but the role of vitamin $\mathrm{D}$, and the extent to which it has direct effects on normal muscle strength and physical function remains controversial [38]. The potential mechanisms that link vitamin D status to muscle function are complex and include both genomic and no genomic roles $[37,39]$. The vitamin D receptor (VDR) has been isolated from skeletal muscle, indicating that it is a target organ [37], and polymorphisms of the VDR have been shown to be related to differences in muscle strength [40]. At the genomic level, binding of the biologically active form of the vitamin (1, 25-dihydroxyvitamin D) results in enhanced transcription of a range of proteins, including those involved in calcium metabolism [37]. The no genomic actions of vitamin D are currently less well understood [39].

Much of the epidemiological literature is consistent with the possibility that there are direct effects of vitamin D on muscle strength. For example, among men and women aged 60 years and older, low vitamin D status (serum 25-hydroxyvitamin D $<15 n g$ mL-1) was associated with a fourfold increase in risk of frailty $[24,41]$, and in a meta-analysis of supplementation studies of older adults have showed that supplemental vitamin D (700-1000IU per day) reduced the risk of falling by $19 \%$. However, the evidence is not always consistent as some research studies find no association between vitamin D status and physical function, and supplementation studies have not always resulted in measurable improvements in function [12,21]. In a review of published studies, discuss the reasons for due to methodological differences, including a lack of consideration of confounding influences in some studies. Further evidence is needed, particularly as vitamin D insufficiency is common among older adults $[38,41]$.

\section{Antioxidant Nutrients and Polyunsaturated Fatty Acids (PUFAs)}

There is increasing interest in the role of oxidative stress in a etiology of sarcopenia, and markers of oxidative damage have been shown to predict impairments in physical function in older adults [42]. Damage to biomolecules such as DNA, lipid, and proteins may occur when reactive oxygen species (ROS) are present in cells in excess. The actions of ROS are opposite effect to musicaldamaged by antioxidant defense mechanisms that include the enzymes superoxide dismutase and glutathione peroxidase, as well exogenous antioxidants derived from the diet, such as selenium, carotenoids, tocopherols, flavonoids, and other plant polyphenols [32-42]. In older age, an accumulation of ROS may lead to oxidative damage and contribute to losses of muscle mass and strength [32].

A number of observational studies have shown positive associations between higher antioxidant status and measures of physical function [27]. Importantly these associations are seen both in cross-sectional analyses and in longitudinal studies, such that poor status is predictive of decline in function. There are higher plasma carotenoid concentrations were associated with a lower risk of developing a severe walking disability over a follow-up period of 6 years among older men and women, after taking substances of antioxidant nutrients that included level of physical activity and other morbidity, the odds ratio was 0.44 (95\% CI 0.27-0.74)[43]. Inverse associations have also been 
described for vitamin E and selenium status and risk of impaired physical function [27]. There have been few studies of older adults to determine how antioxidant supplementation affects muscle strength, and the benefits of supplementation remain uncertain [44]. Since ROS have both physiological and pathological roles, interventions based on simple suppression of their activities may be unlikely to improve age-related declines in muscle mass and function [45]. However, low antioxidant intakes and status are common [46], and this remains an important question to be addressed.

Sarcopenia is increasingly identified as an inflammatory state driven by cytokines and oxidative stress [47]. Since eicosanoids derived from 20-carbon polyunsaturated fatty acids are among the mediators and regulators of inflammation [30], this raises the possibility that many of different types oils in intake of n- 3 and n- 6 PUFAs, and their balance in the diet, could be of importance. In particular, n-3 PUFAs have the potential to be potent anti-inflammatory agents [30]. There is some observational evidence to support an effect of $n-3$ LCPUFA status on muscle function, as higher grip strength was found in older men and women who had greater consumption of oily fish [48]. Consistent with this finding, a number of studies of patients with rheumatoid arthritis have shown that supplementation with fish oil resulted in improved grip strength [30]. In a recent randomized controlled trial, supplementation of older adults with n-3 PUFA (eicosapentaenoic and docosahexaenoic acids) resulted in an enhanced anabolic response to amino acid and insulin infusion. These novel data suggest that the stimulation of muscle protein synthesis by n-3 LCPUFA supplementation could be useful for the prevention and treatment of sarcopenia [49], further evidence is needed to establish the nutrition care process for potential of n-3 PUFAs in inflammatory conditions [30].

\section{Foods and Dietary Patterns}

One problem with the existing evidence base is that dietary components are often highly correlated with each other. This may help to explain why the effects of supplementation with single nutrients may be less than that predicted by the research evidence. It also means that from researchable data it may be difficult to understand the relative importance of the influences of different nutrients on sarcopenia. For example, with an antioxidant nutrient such as $\beta$-carotene may be causally related to variations in physical function, it may also be acting as a marker of other components of fruit and vegetables. Since diets are patterned, high fruit and vegetable consumption may be indicators of other dietary differences which could be important for muscle function, such as greater consumption of oily fish and higher intakes of vitamin D and n-3 LCPUFAs [50]. Having a result that increases in effects of nutrient deficiencies have been identified. To estimated that each additional nutrient deficiency raised the risk of frailty in older women by almost $10 \%$ [51]. This emphasizes the importance of the quality of diets of older adults, as well as the quantity of food consumed, to ensure that intakes of a variety of nutrients are sufficient.
Compared with the evidence that links variations in nutrient intake and status to physical function, much less is known about the influence of dietary patterns and dietary quality in older age. "Goodbalance" diets, characterized by greater fruit and vegetable consumption, whole meal cereals, and oily fish, have been shown to be associated with greater muscle strength in older adults [48]. Data from studies of younger adults appear to be consistent with this finding. For example, among women aged 42-52 years, "unhealthy" diets, defined by higher saturated fat intakes and lower fruit and vegetable consumption, were associated with greater functional limitations over a 4-year follow-up period [52]. Benefits of healthier diets and greater fruit and vegetable consumption on physical function in midlife have also been described in women and men study [53,54]. Intervention studies that take a food-based or "balance diet" approach are likely to change intakes of a variety of nutrients and, therefore, have the potential to be more effective than single nutrient supplementation studies in preventing age-related losses in muscle mass and strength.

\section{Diet and Physical Activity}

Resistance exercise training interventions have been shown to be effective in increasing muscle strength and improving physical function in older adults [55]. A further issue in understanding a possible protective role for diet in sarcopenia is, therefore, the potential for interactions between diet and exercise, and the extent to which interventions that combine supplementation and exercise training may be more effective than changing nutrient intake alone. The interactive effects of diet and exercise on physical function have been studied most extensively in relation to protein/amino acid supplementation. For example, in consumption of a high protein meal has been shown to increase muscle protein synthesis in older adults by $\sim 50 \%$, combining a high protein meal with resistance exercise increases synthesis more than $100 \%$ [56]. However, a number of studies of older adults have failed to show additional benefits of protein/amino acid supplementation on the skeletal muscle response to prolonged resistance exercise training [32,57], and the implications for long-term effects of combined exercise training and high protein intakes are, therefore, not clear [33]. The need for further research-particularly to address the effects of differing quantity and timing of supplementation [56,57]. At present we have limited information into the combined effects of vitamin D supplementation and resistance exercise on muscle strength and function [58].

\section{Lifelong Nutrition and Sarcopenia}

Firstly, the health of older people is depend on lifelong experience to a healthy diet and lifestyle [27]. Although there is evidence that healthier eating behaviors are reasonably stable in adult life [59]. The influence of lifelong nutrition on age-related changes in muscle mass and strength has been little studied, but in terms of interventions to delay or prevent sarcopenia in older age, there may be key factors earlier in the lifetime that need to 


\section{Journal of Endocrinology and Thyroid Research}

be identified. A second consideration is that muscle mass and strength achieved in later life are not only determined by the rate of muscle loss, but also reflect the peak attained in early life. Thus, factors that influence growth, such as variations in early nutrition, may contribute to muscle mass and strength in older age.

It is importance of life time influences, is that low weight at birth predicts lower muscle mass and strength in adult life. This is a consistent finding by a number of studies. Although little is currently known about the influence of diet in early life on sarcopenia, recent studies of adolescents have provided evidence of nutrient effects on muscle mass and function earlier in the lifetimes. Consistent with studies of older adults, low vitamin D status has been shown to be associated with lower grip strength and with poorer muscle power and velocity. However, randomized controlled trials of vitamin D supplementation of adolescents have had mixed results. Among premenarcheal girls who were supplemented with vitamin D over 1 year, there were rank increases in lean mass, although supplementation did not result in measurable differences in grip strength( 64 ) In contrast, vitamin D supplementation of adolescent boys and postmenarcheal girls has not been shown to be effective in increasing lean mass or muscle strength or power. There are concluded that earlier interventions, before the period of peak muscle mass increased, may be needed to improve muscle function and physical performance.

To date, few studies have examined the role of diet in early childhood in the act of getting of muscle mass and effects on later function, although there is some evidence that it could be important. For example, the risk of frailty has been shown to be greater in older adults who grew up poor in quality conditions, and who experienced hunger in childhood. However, animal models suggest that nutrition even earlier in life may be key, as muscle growth in the neonatal period is highly sensitive to variations in nutrient intake. Among children, duration of breastfeeding was not associated with physical work capacity assessed at the age 9 years, in adolescents studied, longer duration of breastfeeding was associated with measurable differences in physical performance-particularly in lower body explosive strength. Consistent with longer duration of breastfeeding and greater compliance with infant feeding guidance has been shown to be associated with greater lean mass in later childhood. Dietary patterns marks across childhood, and this may simply reflect continuing benefits of healthier diets. However, it does suggest that variations in early postnatal diet could have implications for muscle function in later life.

We currently know little about the contribution of nutrition throughout the lifetimes to muscle mass and strength in adult life, and further work is needed to understand how early nutrition influences the act of getting of peak muscle mass, and the role played by nutrition of age-related losses in muscle function. Taking a life time approach to understanding the links between nutrition and muscle mass and function in older age could change dietary strategies to prevent sarcopenia in the future.

\section{Conclusion}

To develop strategies to prevent or delay sarcopenia, a better understanding is needed of the lifestyle factors that influence the rate of decline of muscle mass and strength in older age, and the mechanisms involved. Existing evidence indicates the potential importance of diets of adequate quantity and quality, to ensure sufficient intakes of protein, vitamin D, and antioxidant nutrients. Although much of this evidence is observational and the mechanisms are not fully understood, the high prevalence of low nutrient intakes and poor status among older adults make this a current concern. However, muscle mass and strength achieved in later life are not only determined by the rate of muscle loss, but also reflect to reach the peak earlier in life, and efforts to prevent sarcopenia also need to identify the potential effectiveness of interventions earlier in the life course. Optimizing diet and nutrition throughout life may be key to preventing sarcopenia and promoting physical capability in older age.

\section{References}

1. Cruz-Jentoft J, Baeyens JP, Bauer JM, Boirie Y, Cederholm T, et al. (2010) Sarcopenia: European consensus on definition and diagnosis: Report of the European Working Group on Sarcopenia in Older People. Age Ageing 39(4): 412-423.

2. Janssen I, Shepard DS, Katzmarzyk PT, Roubenoff R (2004) The healthcare costs of sarcopenia in the United States. J Am Geriatr Soc 52(1): 80-85.

3. Syddall H, Evandrou M, Cooper C, Aihie Sayer A (2009) Social inequalities in grip strength, physical function, and falls among community dwelling older men and women: findings from the Hertfordshire cohort study. J Aging Health 21(6): 913-939.

4. Nieuwenhuizen WF, Weenen H, Rigby P, Hetherington MM (2010) Older adults and patients in need of nutritional support: review of current treatment options and factors influencing nutritional intake. Clin Nutr 29(2): 160-169

5. Murphy (2008) The chemical senses and nutrition in older adults. J Nutr Elder 27(3-4): 247-265.

6. Bartali B, Salvini S, Turrini A, Lauretani F, Russo CR, et al. (2003) Age and disability affect dietary intake. J Nutr 133(9): 2868-2873.

7. Corish CA, Kennedy NP (2000) Protein-energy undernutrition in hospital in-patients.Br J Nutr 83(6): 575-591.

8. Finch S, Doyle W, Lowe C, Bates CJ, Prentice A, et al. (1998) National Diet and Nutrition Survey: people aged 65 years and over. Report of the diet and nutrition survey. The Stationery Office, London, UK, England.

9. Edington J, Kon P, Martyn CN (1996) Prevalence of malnutrition in patient's in general practice. Clin Nutr 15(2): 60-63.

10. Landi F, Zuccala G, Gambassi G, Incalzi RA, Manigrasso L, et al. (1999) Body mass index and mortality among older people living in the community. J Am Geriatr Soc 47(9): 1072-1076.

11. Gariballa SE, Sinclair AJ (1998) Nutrition, ageing and ill health. Br J Nutr 80(1):7-23.

12. Delmi M, Rapin CH, Bengoa JM, Delmas PD, Vasey H, et al. (1990) Dietary supplementation in elderly patients with fractured neck of the femur. Lancet 335(8696): 1013-1016.

13. Robinson G, Goldstein M, Levine GM (1987) Impact of nutritional status on DRG length of stay. JPEN J Parenter Enteral Nutr 11(1): 49-51.

14. Friedmann JM, Jensen GL, Smiciklas WH, McCamish MA (1997) Predicting early nonelective hospital readmission in nutritionally compromised older adults. Am J Clin Nutr 65(6): 1714-1720. 
15. Kaiser M, Bandinelli S, Lunenfeld B (2010) Frailty and the role of nutrition in older people. A review of the current literature. Acta Biomed 81(suppl1): 37-45.

16. Ha L, Hauge T, Spenning AB, Iversen PO (2010) Individual, nutritional support prevents undernutrition, increases muscle strength and improves QoL among elderly at nutritional risk hospitalized for acute stroke: a randomized, controlled trial. Clin Nutr 29(5): 567-573.

17. Bischoff-Ferrari HA, Dawson-Hughes B, Staehelin HB, Orav JE, Stuck AE, et al. Fall prevention with supplemental and active forms of vitamin D: a meta-analysis of randomized controlled trials. British Medical Journal 339.

18. Calder PC (2006) n-3 polyunsaturated fatty acids, inflammation, and inflammatory diseases. Am J Clin Nutr 83(suppl 6): 1505S-1519S.

19. Wolfe RR, Miller SL, Miller KB (2008) Optimal protein intake in the elderly. Clin Nutr 27(5): 675-684.

20. Kim S, Wilson JM, Lee SR (2010) Dietary implications on mechanisms of sarcopenia: roles of protein, amino acids and antioxidants. J Nutr Biochem 21(1): 1-13.

21. Paddon-Jones, Rasmussen BB (2009) Dietary protein recommendations and the prevention of sarcopenia. Curr Opin Clin Nutr Metab Care 12(1): 86-90.

22. Houston DK, Nicklas BJ, Ding J, Harris TB, Tylavsky FA, et al. (2008) Dietary protein intake is associated with lean mass change in older community-dwelling adults: the Health, Aging, and Body Composition (Health ABC) study. Am J Clin Nutr 87(1): 150-155.

23. Børsheim E, Bui QT, Tissier S, Kobayashi H, Ferrando AA, et al. (2008) Effect of amino acid supplementation on muscle mass, strength and physical function in elderly. Clin Nutr 27(2): 189-195.

24. Milne C, Potter J, Vivanti A, Avenell A, (2009) Protein and energy supplementation in elderly people at risk from malnutrition. Cochrane Database Syst Rev 2: CD003288.

25. Hamilton B (2010) Vitamin D and human skeletal muscle. Scand J Med Sci Sports 20(2): 182-190.

26. Annweiler C, Schott AM, Berrut G, Fantino B, Beauchet O (2009) Vitamin D-related changes in physical performance: a systematic review. J Nutr Health Aging 13(10): 893-898.

27. Ceglia L (2009) Vitamin D and its role in skeletal muscle. Curr Opin Clin Nutr Metab Care 12(6): 628-633.

28. Geusens P, Vandevyver C, Vanhoof J, Cassiman JJ, Boonen S, et al. (1997) Quadriceps and grip strength are related to vitamin $\mathrm{D}$ receptor genotype in elderly no obese women. J Bone Miner Res 12(12): 2082-2088.

29. Wilhelm-Leen ER, Hall YN, de boer IH, Chertow GM (2010) Vitamin D deficiency and frailty in older Americans. J Intern Med 268(2): 171180.

30. Semba RD, Ferrucci L, Sun K, Walston J, Varadhan R, et al. Oxidative stress and severe walking disability among older women. Am J Med 120(12): 1084-1089.

31. Lauretani F, Semba RD, Bandinelli S, Dayhoff-Brannigan M, Lauretani $\mathrm{F}$, et al. Carotenoids as protection against disability in older persons. Rejuvenation Res 11(3): 557-563.

32. Fusco D, Colloca G, Lo Monaco MR, Cesari M (2007) Effects of antioxidant supplementation on the aging process. Clin Interv Aging 2(3): 377-387.

33. Jackson MJ (2009) Strategies for reducing oxidative damage in ageing skeletal muscle. Adv Drug Deliv Rev 61(14): 1363-1368.

34. Stimpson JP, Nash AC, Ju H, Eschbach K (2007) Neighborhood deprivation is associated with lower levels of serum carotenoids among adults participating in the third national health and nutrition examination survey. J Am Diet Assoc 107(11): 1895-1902.
35. Jensen L (2008) Inflammation: roles in aging and sarcopenia. JPEN J Parenter Enteral Nutr 32(6): 656-659.

36. Robinson SM, Jameson KA, Batelaan SF et al. (2008) Diet and its relationship with grip strength in community-dwelling older men and women: the Hertfordshire cohort study. J Am Geriatr Soc 56(1): 84-90.

37. Smith GI, Atherton P, Reeds DN, Mohammed BS, Rankin D, et al. Dietary omega-3 fatty acid supplementation increases the rate of muscle protein synthesis in older adults: a randomized controlled trial. Am J Clin Nutr 93(2): 402-412.

38. Robinson S, Syddall H, Jameson K, Batelaan S, Martin H, et al. (2009) Current patterns of diet in community-dwelling older men and women: results from the Hertfordshire cohort study. Age Ageing 38(5): 594599.

39. Semba RD, Bartali B, Zhou J, Blaum C, Ko CW, et al. (2006) Low serum micronutrient concentrations predict frailty among older women living in the community. J Gerontol A Biol Sci Med Sci 61(6): 594-599.

40. Tomey KM, Sowers MR, Crandall C, Johnston J, Jannausch M, et al. (2008) Dietary intake related to prevalent functional limitations in midlife women. Am J Epidemiol 167(8): 935-943.

41. Stafford M, Hemingway H, Stansfeld SA, Brunner E, Marmot M, et al. (1998) Behavioral and biological correlates of physical functioning in middle aged office workers: the UK Whitehall II study. J Epidemiol Community Health 52(6): 353-358.

42. Houston DK, Stevens J, Cai J, Haines PS (2005) Dairy, fruit, and vegetable intakes and functional limitations and disability in a biracial cohort: the atherosclerosis risk in communities study. Am J Clin Nutr 81(2): 515-522.

43. Liu CJ, Latham NK (2009) Progressive resistance strength training for improving physical function in older adults. Cochrane Database Syst Rev 3: CD002759.

44. Symons TB, Sheffield-Moore M, Mamerow MM, Wolfe RR, Paddon-Jones D (2010) The anabolic response to resistance exercise and a protein-rich meal is not diminished by age. J Nutr Health Aging 15(5): 376-381.

45. Koopman R (2010) Exercise and protein nutrition: dietary protein and exercise training in ageing. Proc Nutr Soc 70(1): 104-113.

46. Bunout D, Barrera G, Leiva L, Gattas V, de la Maza MP, et al. Effects of vitamin $\mathrm{D}$ supplementation and exercise training on physical performance in Chilean vitamin D deficient elderly subjects. Exp Gerontol 41(8): 746-752.

47. Mishra GD, McNaughton SA, Bramwell GD, Wadsworth MEJ (2006) Longitudinal changes in dietary patterns during adult life. Br J Nutr 96(4): 735-744.

48. Sayer A, Syddall H, Martin H, Patel H, Baylis D, et al. (2008) The developmental origins of sarcopenia. J Nutr Health Aging 12(7): 427-431.

49. Sayer A (2010) Sarcopenia. British Medical Journal 341: c4097.

50. Foo LH, Zhang Q, Zhu K, Ma G, Hu X, et al. (2009) Low vitamin D status has an adverse influence on bone mass, bone turnover, and muscle strength in Chinese adolescent girls. J Nutr 139(5): 1002-1007.

51. Ward KA, Das G, Berry JL, Roberts SA, Rawer R, et al. (2009) Vitamin D status and muscle function in post-menarchal adolescent girls. J Clin Endocrinol Metab 94(2): 559-563.

52. Fuleihan GEH, Nabulsi M, Tamim H, Maalouf J, Salamoun M, et al. (2006) Effect of vitamin D replacement on musculoskeletal parameters in school children: a randomized controlled trial. J Clin Endocrinol Metab 91(2): 405-412.

53. Ward KA, Das G, Roberts SA, Berry JL, Adams JE, et al. A randomized, controlled trial of vitamin D supplementation upon musculoskeletal health in post-menarchal females. J Clin Endocrinol Metab 95(10): 4643-4651. 
54. Alvarado E, Zunzunegui MV, Béland F, Bamvita JM (2008) Life course social and health conditions linked to frailty in Latin American older men and women. J Gerontol A Biol Sci Med Sci 63(12): 1399-1406.

55. Davis TA, Fiorotto ML (2009) Regulation of muscle growth in neonates. Curr Opin Clin Nutr Metab Care 12(1): 78-85.

56. Lawlor A, Cooper AR, Bain C, Davey Smith G, Irwin A, et al. (2008) Associations of birth size and duration of breast feeding with cardiorespiratory fitness in childhood: findings from the Avon Longitudinal Study of Parents and Children (ALSPAC). Eur J Epidemiol 23(6): 411-422.

57. Artero G, Ortega FB, Espana-Romero V, Idoia Labayen, Inge Huybrechts, et al. (2010) Longer breastfeeding is associated with increased lower body explosive strength during adolescence. Journal of Nutrition 140(11): 1989-1995.
58. Robinson SM, Marriott LD, Crozier SR, et al. Variations in infant feeding practice are associated with body composition in childhood: a prospective cohort study. J Clin Endocrinol Metab 94(8): 2799-2805.

59. Northstone K, Emmett PM (2008) Are dietary patterns stable throughout early and mid-childhood? A birth cohort study. Br J Nutr 100(5): 1069-1076.

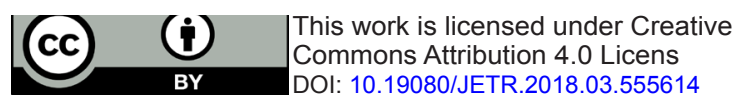

\section{Your next submission with Juniper Publishers will reach you the below assets}

- Quality Editorial service

- Swift Peer Review

- Reprints availability

- E-prints Service

- Manuscript Podcast for convenient understanding

- Global attainment for your research

- Manuscript accessibility in different formats ( Pdf, E-pub, Full Text, Audio)

- Unceasing customer service

Track the below URL for one-step submission https://juniperpublishers.com/online-submission.php 